\title{
THE EFFECT OF SELF-AWARENESS AND SELF-REGULATION ON ORGANIZATIONAL COMMITMENT EMPLOYEES OF ISLAMIC AZAD UNIVERSITY OF MASHHAD WITH MEDIATING ROLE OF JOB SATISFACTION
}

\author{
M. Pourkiani ${ }^{1 *}$, S. M. Seyedi ${ }^{2}$, H. S. Sarasia ${ }^{2}$ \\ ${ }^{1}$ Department of Management, Facultyof HumanSciences, Islamic Azad University Kerman \\ Branch, Kerman, Iran \\ ${ }^{2} \mathrm{PhD}$ student in public administration, Islamic Azad University, Kerman Branch, IRAN
}

Published online: 18 July 2016

\begin{abstract}
Optimal utilization of employees and facilities is the primary goal of any organization and creation of a commitment and satisfaction in employees can have a major role to realize the goals. The aim of this study is to investigate The Effect of Self-awareness and Self-regulation on Organizational Commitment Employees of Islamic Azad University of Mashhad with Mediating Role of Job Satisfaction. The statistical sample of the study is the employees of Islamic Azad University of Mashhad which is obtained through simple random sampling according to the sample size of Cochran's formula, 190 questionnaires were collected. The collected data from the questionnaires were analyzed with structural equation modeling method using LISREL software. Also Spss software was used to express the descriptive statistics data. The results of this study showed that self-awareness and self-regulation has a positive effect on organizational commitment and job satisfaction. Also job satisfaction has a positive effect on organizational commitment and finally the results suggest the effectiveness of Self-awareness and Selfregulation on organizational commitment job satisfaction with mediating role of job satisfaction.
\end{abstract} Keywords: Self-awareness, Self-regulation, Job Satisfaction, Organizational Commitment.

Author Correspondence, e-mail: pourkaini@yahoo.com

doi: http://dx.doi.org/10.4314/jfas.v8i2s.130 


\section{INTRODUCTION}

Since then the opinion of scientists such as Peter Salovey and John Mayer (1990) was attracted to other capabilities that were more of emotion type than cognitive type. These capabilities that were called emotional intelligence refer to the taught abilities that help us understand our emotions to work for our benefit, not against us (Dehshiri, 2004). Goleman (2004), says in his best-selling book called Emotional Intelligence: In professional and personal success emotional intelligence skills can play a more important role than the conventional or general intelligence. Self-awareness and Self-regulationnot only brings success in career and intrapersonal relationships, but also can lead to organizational success. Considering the importance of emotional intelligence in success and job satisfaction and organizational commitment is also decisive impact on the performance of the individual and society, the aim of this study was to evaluate the effects of emotional intelligence as well as the effect of job satisfaction and organizational commitment on the individual and social efficiency, the goal of this study is to investigate the effect of Self-awareness and Self-regulation on Organizational Commitment Employees of Islamic Azad University of Mashhad with Mediating Role of Job Satisfaction In fact, this research seeks to answer the question that How would be the effects of Self-awareness and Self-regulation on organizational commitment with the mediating role of job satisfaction, among the employees in Islamic Azad University of Mashhad?

\section{Theoretical Foundations}

\section{Self-awareness and Self-regulation}

The components of Emotional Intelligence according to Goleman's views (1998):

1. Emotional self-awareness: correct assessment, confidence.

2. Self-regulation: self-control, trustworthiness, vigilance, adaptability, innovation.

3. Motivation: achievement, commitment, initiative, optimism.

4. Empathy: understanding others, diversity, political awareness.

5. Social skills: influence, communication, conflict management, leadership, organizing change, limiting, partnership and cooperation, teamwork capacities (Ciarrochi, 2005).

Emotional intelligence at work: utilizing the emotional intelligence is very good method that focuses energy in one direction and brings an excellent result. Emotional intelligence is so essential for career success that includes $60 \%$ performance in all types of jobs. Emotional intelligence is the single largest factor for predicting individual performance in the workplace and the strongest force for leadership and success. Perhaps the best advantage of emotional intelligence is that it is a very flexible skill. No matter how high or low is the emotional intelligence of people, they are still able to improve it with practice and those who score low in 
emotional intelligence can actually catch up with their colleagues at the end. (Bradbury and Graves, 2005). Understanding emotions cause people to gain insight into their motivations, it makes us aware towards the points of view and opinions of others. Finally, management of emotions allows us to recognize our emotions use the obtained valuable information in a constructive way (Ciarrochi, 2005).

\section{Organizational Commitment}

In this study the means of organizational commitment is staffs commitments to their organization. Different people have defined commitment in different ways. Some of them are reviewed as below:

Organizational commitment is an important job attitude which has been desired for many researchers of organizational behavior field in last years. In another definition, organizational commitment has consider as an emotional dependency to the organization. Based on this approach, a person who is strongly committed, takes his identity from the organization, participate in the organization and blends in it and enjoy his membership in the organization (Sarooghi, 1996).

Porter et al. (1974) define organizational commitment as accepting organization values and getting involved in the organization and its measuring criteria involve motivation, desire to continue and accept the values of the organization are key factors which lead to the organization finance success and its competitive advantages. Yaghoubi (2009) Defines organizational commitments as people bonding with the organization which is determined by three factors: a strong belief and accept the goals and values of the organization (emotional commitment) tend to be hard work for the organization (continuance commitment), and a strong desire to stay in the organization (normative commitment). In general it can be said: staffs commitment is an attitude and a strong desire to stay in the organization and efforts on tasks and faith to accept the values and goals of the organization, it must be explained the nature of organizational commitment is complex and has various dimensions (commitment to themselves, to the organization, to clients, etc.) that naturally have different results from an organization to another with the consideration of human factors, cultural factors, social factors, etc.

Allen and Meyer (1990) present three-part model for organization commitment including normative commitment, emotional commitment and continuous commitment that in present study normative and continuous commitments are more considered. These authors, describe relevant articles of organization commitment in this way: staffs with high levels of emotional commitment will stay in the organization due to their own demands. In fact emotional commitment refers to staffs emotional dependency to the organization, nature and their relations 
with the organization. Continuous commitment refers to understanding about costs of leaving the organization. Individuals who possess high levels of continuous commitment, stay in the organization due to their needs to the organization. Normative commitment is a reflection of sense of duty to continue serving. Staffs with high levels of normative commitment, stay in the organization due to they feel that they have to stay in the organization.

\section{Job Satisfaction}

According to many experts, among all concepts that the organizational behavior psychologists and experts studied, job satisfaction has been the most important research areas. For this reason, multiple and sometimes conflicting views and conceptualizations have been formed and developed about it. (Houman, 2001). Job satisfaction is a collection of agreeable and disagreeable sensations which staffs see their work with. Ginsberg et al. (1951) divide job satisfaction to two different types:

1- Internal satisfaction: that obtains from tow resource. First, enjoy sensation that obtains merely from engagement to work and job activities. The Second enjoy which obtains from observe the promotion or doing some social responsibilities and display abilities and individual propensity.

2- External satisfaction: that is related with engagement conditions and work environment and that is changing all the time. The external satisfactions factors can be named as: work environment conditions, wage amount and work type rewards and relations between employee and employer. Generate job satisfactions in staffs possibly is not a fast process but it definitely lost with high acceleration. It is possible that all of factors exist for remaining high levels of job satisfactions but the impact of these factors will disappear only if a manager has a mistreatment. Job satisfactions are positive emotions level that a person have about his job. When a person says he/she have high level of job satisfactions it means that he/she actually love his/her job, have good emotions about his/her work and his/her job is valuable for him (Moghaddasi, 2010).

\section{Research Hypotheses:}

1. Self-awareness (awareness of one's emotions) affects organizational commitment of the employees of Azad University of Mashhad

2. Self-regulation (managing emotions) affects organizational commitment of the employees of Azad University of Mashhad

3. Self-awareness (awareness of one's emotions)affects job satisfaction of the employees of Azad University of Mashhad

4. Self-regulation (managing emotions) affects job satisfaction of the employees of Azad University of Mashhad 
5. Job Satisfaction affects organizational commitment of the employees of Azad University of Mashhad

6. Self-awareness and Self-regulation affects organizational commitment Employees of Islamic Azad University of Mashhad with Mediating Role of Job Satisfaction.

\section{Conceptual Model of the Research:}

The main variables included in the model, are three variables called Self-awareness and Selfregulation, organizational commitment, and job satisfaction. The first variable i.e. Selfawareness and Self-regulation is the independent variable of the study which may directly and indirectly influence on organizational commitment. Thus, the organizational commitment is a dependent variable which may be affected by the other two variables. But what has distinguished this study from others is a mediator variable in the model that is effective on organizational commitment. This mediator variable is "job satisfaction". Therefore, in this study, job satisfaction is considered as a mediator or intermediary. This model is presented as follows:

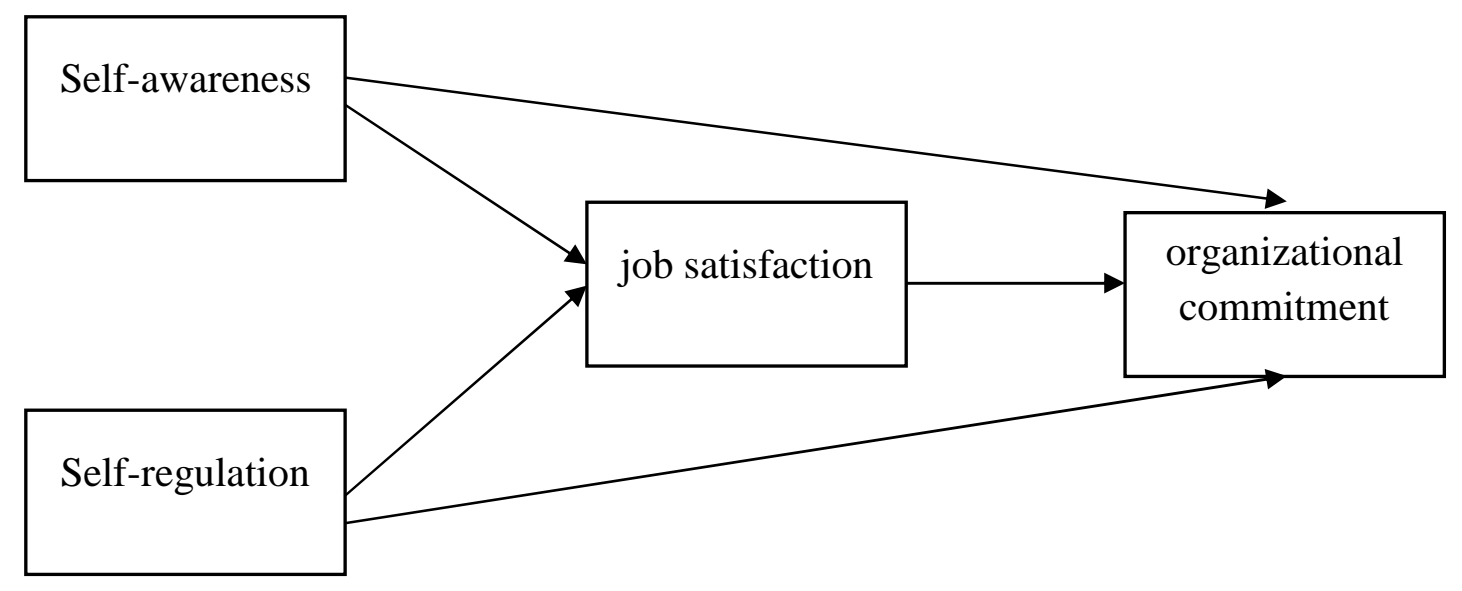

Fig.1. Conceptual Model of the Research

\section{Research Methodology}

The research method is a set of rules, tools and valid, reliable and systematic ways for the investigation of the facts, discovering the unknown and achieving a solution to the problems. The basis of each science is its methodology and validity and law values of each science are based on the methodology that is used in that science (Ezzati, 2010). In this study, the research is applied in terms of purpose and analytical survey in terms of data collection. The collected data from the questionnaires were analyzed with structural equation modeling method using LISREL software and the Spss software was used to express the descriptive statistics data. 


\section{Measures and their validity and reliability}

To measure the variables the proposed measures in studies of Bar-on (2000) used for emotional intelligence and Alan and Mayer (2004) for organizational commitment and Minnesota (1969) was used for job satisfaction and a questionnaire was designed with 28 items. To adapt the questionnaires with the commercial context in Iranian organizations, the perspective of people in this field was used. The face and content validity of the final questionnaire was approved by opinion of managements. Besides the construct validity of the questionnaire and dimensions of each of them was evaluated using confirmatory factor analysis techniques and significant load of each of these dimensions and items related to the desired constructs were confirmed. It is worth noting that all questionnaire items were assessed using a five point Likert scale, ranging from strongly disagree to strongly agree. In addition, the internal consistency of the used instrument were measured using Cronbach's alpha coefficient which is reported in the table below.

Table 1. Results of questionnaire reliability

\begin{tabular}{|c|c|c|c|c|}
\hline Variables & $\begin{array}{c}\text { Self- } \\
\text { awareness }\end{array}$ & $\begin{array}{c}\text { Self- } \\
\text { regulation }\end{array}$ & $\begin{array}{c}\text { organizational } \\
\text { commitment }\end{array}$ & $\begin{array}{c}\text { job } \\
\text { satisfaction }\end{array}$ \\
\hline $\begin{array}{c}\text { Cronbach's } \\
\text { alpha }\end{array}$ & 0.845 & 0.725 & 0.831 & 0.793 \\
\hline
\end{tabular}

\section{Population and sampling method}

Employees working in Islamic Azad University of Mashhad in different employment levels is the subject of this study. Because this study is applied based on the type and purpose of the research and representativeness of the sample for the purposes of generalizability to the community is important, so the simple random sampling is used. First, an initial sample of 30 questionnaire was pretested from experts, and through placing its SD to 50\% in Cochran's formula it was accurately estimated and the confidence level determined to be 0.95 and the minimum sample size was set 188 subjects. Given the prediction that some of the questionnaires will not be returned, 200 questionnaires were randomly distributed between experts, and of these, 190 questionnaires were returned. Finally, the number of qualified questionnaires were used in the analysis process.

\section{Findings of the Research}

Profile of the subjects 
Profile of respondents in this study was studied using the five demographic variables of age, sex, education, and job merely to report the appearance of subjects. The following table shows the summary of these results.

Table 2. Variable frequency

\begin{tabular}{|c|c|c|}
\hline demographic variables & state & Frequency \\
\hline \multirow{2}{*}{ gender } & woman & 35.7 \\
\hline & man & 64.3 \\
\hline \multirow{4}{*}{ age } & under 30 years & 22.4 \\
\hline & $30-40$ years & 56.5 \\
\hline & $41-50$ years & 18.9 \\
\hline & Over50years & 2.2 \\
\hline \multirow{3}{*}{ education } & Diploma and upon Diploma & 29.6 \\
\hline & Masters & 54.1 \\
\hline & Mastersand higher & 16.4 \\
\hline \multirow{6}{*}{ Job Experience } & Under 5 years & 8.8 \\
\hline & $6-10$ years & 19.5 \\
\hline & $11-15$ years & 34.6 \\
\hline & $16-20$ years & 24.5 \\
\hline & $21-25$ years & 8.2 \\
\hline & Over 25 years & 4.4 \\
\hline \multirow{2}{*}{ marriage situation } & married & 81.8 \\
\hline & single & 18.2 \\
\hline
\end{tabular}

As the results showed, the number of men $(64.3 \%)$ was more than women (35.7\%), the majority age from 30 to 40 years $(56.5 \%)$ and those with a Masters 's degree $(54.1 \%)$ and Job Experience11 - 15 years $(34.6 \%)$ had the largest share in the sample.alsothe number of married $(81.8 \%)$ was more than single $(18.2 \%)$

\section{Kolmogorov-Smirnov test}

By using Kolmogorov-Smirnov test it is possible to examine the normal distribution of data of a variable. In this study, this test was used to assess the normality of the variables of questionnaire, so that by establishing this condition we use the likelihood ratio method in structural equation.Given that the significance level of the test is related to all variables higher than 0.05 , the normality of variables was accepted and the likelihood ratio method can be used in structural equation modeling. 


\section{Validation and confirmatory factor analysis}

Before fitting the structural model and to assess the significance load of the questionnaire items to the relevant structures, we need to do the confirmatory factor analysis and make sure of the measurement models (latent variables) to predict the path coefficients. The results of confirmatory.factor analysis are shown in the following table:

Table 4. Confirmatory factor analysis variables (construct validity)

\begin{tabular}{|c|c|c|c|c|c|c|c|c|c|}
\hline Item & 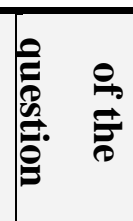 & 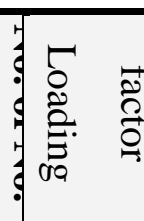 & 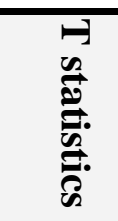 & (SE) & Item & 2. & 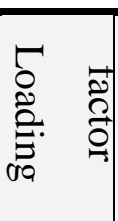 & 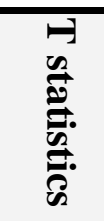 & (SE) \\
\hline \multirow{7}{*}{$\begin{array}{c}\text { Self- } \\
\text { awareness }\end{array}$} & sa1 & 0.98 & 9.23 & 0.11 & \multirow{7}{*}{$\begin{array}{l}\text { organizational } \\
\text { commitment }\end{array}$} & Oc1 & 0.51 & 8.49 & 0.06 \\
\hline & $\mathrm{sa} 2$ & 0.64 & 8.93 & 0.07 & & Oc2 & 0.63 & 10.25 & 0.06 \\
\hline & sa3 & 0.52 & 6.17 & 0.08 & & Oc3 & 0.47 & 4.57 & 0.10 \\
\hline & sa4 & 0.38 & 5.31 & 0.07 & & Oc4 & 0.39 & 8.9 & 0.04 \\
\hline & sa5 & 0.58 & 4.43 & 0.13 & & Oc5 & 0.52 & 4.22 & 0.12 \\
\hline & sa6 & 0.73 & 9.14 & 0.079 & & Oc6 & 0.54 & 5.33 & 0.10 \\
\hline & $\mathrm{Sa} 7$ & 0.55 & 10.55 & 0.052 & & Oc7 & 0.48 & 9.85 & 0.049 \\
\hline \multirow{7}{*}{$\begin{array}{l}\text { Self- } \\
\text { regulation }\end{array}$} & sr1 & 0.71 & 9.22 & 0.077 & \multirow{7}{*}{$\begin{array}{l}\text { job } \\
\text { isfaction }\end{array}$} & js1 & 0.51 & 5.36 & 0.10 \\
\hline & $\mathrm{Sr} 2$ & 0.85 & 8.98 & 0.095 & & Js2 & 0.76 & 7.71 & 0.10 \\
\hline & Sr3 & 0.31 & 6.77 & 0.05 & & Js3 & 0.59 & 8.99 & 0.07 \\
\hline & $\mathrm{Sr} 4$ & 0.47 & 3.95 & 0.12 & & Js4 & 0.4 & 2.38 & 0.17 \\
\hline & Sr5 & 0.56 & 7.85 & 0.07 & & Js5 & 0.44 & 4.22 & 0.10 \\
\hline & Sr6 & 0.35 & 8.4 & 0.04 & & Js6 & 0.72 & 8.28 & 0.087 \\
\hline & Sr7 & 0.43 & 8.85 & 0.05 & & Js7 & 0.65 & 9.41 & 0.069 \\
\hline
\end{tabular}

Then using Lisrel software, CFA models fitted-out for each 3 research variables and based on regression coefficients or factor loadings signification and model fitting indexes were evaluated. Based on this, the factor loading of all questionnaire items was significant in confidential level of $95 \%$ (with signification numbers greater than 1.96 as well as factor loading greater than 0.3), so all of them were the bases for further Analysis and examining the research Hypotheses 


\section{Models fitting evaluation}

Modelfitting means that how our model is adapted with relevant data. In structural equation analysis, after parameters estimation and before interpretation them it is necessary to ensure about model fitting. Model fitting indexes were evaluated in the following table.

Table 4. Fitting indices

\begin{tabular}{|c|c|c|c|}
\hline Test name & Explanations & $\begin{array}{c}\text { Accepted } \\
\text { values }\end{array}$ & $\begin{array}{c}\text { Resulted } \\
\text { values }\end{array}$ \\
\hline$\chi 2 . \mathrm{df}$ & Relative qui-square & $<3$ & 2.21 \\
\hline RMSEA & $\begin{array}{c}\text { Approximate error } \\
\text { second exponent average } \\
\text { root }\end{array}$ & $<0.1$ & 0.075 \\
\hline GFI & Adjusted propriety index & $>0.9$ & 0.97 \\
\hline RMR & $\begin{array}{c}\text { Remained quadrate } \\
\text { average root }\end{array}$ & $<0.1$ & 0.042 \\
\hline NFI & Soft practice index & $>0.9$ & 0.95 \\
\hline CFI & Comparative practice & $>0.9$ & 0.97 \\
& index & & \\
\hline
\end{tabular}

According to Table 4, the value of RMSEA is equal to 0.075 and according to the fact that it is less than 0.1 it then indicates that the mean squared error of model is appropriate and acceptable. The chi-square value of degrees of freedom is between 1 and 3 and the indices GFI, CFI and NFI are also more than 0.9 that shows that the model for measuring the variables of the research is suitable. Given the verification of the validity and goodness of the model in the next section we test and evaluate the hypotheses using approved dimensions.

\section{Testing the research hypothesis}

In order to test the hypothesis of the structural model, the standardized path coefficients and the corresponding significant numbers were used. This study consists of six hypotheses, the results of which are shown.

First hypothesis: Self-awareness affects organizational commitment of the employees of Azad University of Mashhad

In investigating the effect of Self-awareness on the organizational commitment, the path coefficient between Self-awareness and organizational commitment is equal to 0.14 which is 
a positive value. T-statistic value equals to 15.39 which is more than 1.96 so we can say with 95\% confidence that Self-awareness has a positive significant effect on organizational commitment of employees and the first subsidiary research hypothesis is accepted.

Second hypothesis: Self-regulation affects organizational commitment of the employees of Azad University of Mashhad

In investigating the effect of Self-regulation on the organizational commitment, the path coefficient between Self-regulation and organizational commitment is equal to 0.17 which is a positive value. T-statistic value equals to 17.42 which is more than 1.96 so we can say with 95\% confidence that Self-awareness has a positive significant effect on organizational commitment of employees and the Second research hypothesis is accepted.

The Third hypothesis: Self-awareness affects job satisfaction of the employees of Azad University of Mashhad.

In investigating the effect of self- awareness on the job satisfaction, the path coefficient between self- awareness and job satisfaction is equal to 0.31 which is a positive value. Tstatistic value equals to 16.23 which is more than 1.96 so we can say with $95 \%$ confidence that self- awareness has a positive significant effect on job satisfaction of employees and the third research hypothesis is accepted.

The Fourth hypothesis: self-regulation affects job satisfaction of the employees of Azad University of Mashhad.

In investigating the effect of self- regulation on the job satisfaction, the path coefficient between self- regulation and job satisfaction is equal to 0.41 which is a positive value. Tstatistic value equals to 5.75 which is more than 1.96 so we can say with $95 \%$ confidence that self- regulation has a positive significant effect on job satisfaction of employees and the fourth research hypothesis is accepted.

The Fifth hypothesis: Job Satisfaction affects organizational commitment of the employees of Azad University of Mashhad

In investigating the effect of Job Satisfaction on the organizational commitment, the path coefficient between Job Satisfaction and organizational commitment is equal to 0.53 which is a positive value. T-statistic value equals to 7.89 which is more than 1.96 so we can say with 95\% confidence that Job Satisfaction has a positive significant effect on organizational commitment al of employees and the Fifth research hypothesis is accepted.

The Sixth hypothesis: Self-awareness and Self-regulation affects organizational commitment Employees of Islamic Azad University of Mashhad with Mediating Role of Job Satisfaction. 
Mediation hypothesis has dealt with the mediating role of the job satisfaction in relationship between Self-awareness and Self-regulation and organizational commitment, In other words it has studied the indirect relationship between Self-awareness and Self-regulation and organizational commitment.

To investigate the indirect relationship between the independent variable and the dependent variable the following conditions need to be met first. The first condition is that the significance of the relationship between the independent variable and the mediate should be confirmed and the second condition is that the significance of the relationship between the dependent variable and the mediate should be confirmed. Then in case the above provisions are met, the significant indirect relationship and path coefficient is obtained by the multiplication between the path coefficient of relationship between independent variable with the mediate and the coefficient of the path of relationship between dependent variables. As mentioned in the previous section, the second main hypothesis included the relationship between independent variables and mediate and third main theory included the relationship between dependent an mediate variable so it can be said with regard to the acceptance of these hypothesis that indirect relationship between Self-awareness and Self-regulation and organizational commitment is significant and its coefficient equals:

$$
\begin{aligned}
& 0.16=0.53 * 0.31 \\
& 0.22=0.53 * 0.41
\end{aligned}
$$

According to the results obtained and the Third hypothesis that the path coefficient is equal to 0.31 and Fourth hypothesis that the path coefficient is equal to 0.41 it can be said that the indirect effect between Self-awareness and organizational commitment (0.16) and Selfregulation and organizational commitment $(0.22)$ is less than the direct effect $(0.14),(0.17)$ andSixth hypothesis of research was confirmed.

\section{CONCLUSIONS AND RECOMMENDATIONS}

As mentioned above, the purpose of this study is to investigate the effect of Self-awareness andSelf-regulation on organizational commitment with mediating role of job satisfaction of employees of Islamic Azad University of Mashhad. The results of the study hypothesis tests showed that the emotional intelligence with the two dimensions of self-awareness and selfregulation has a significant positive impact on organizational commitment. In fact, according to this result, people who have a high emotional intelligence tend select a career which matches the needs, values and interests of them. This self-awareness will enable individuals to avoid obstacles such as the anger and emotions of others. The result of this hypothesis is 
confirmed at $95 \%$ which is consistent with the research results of Rezaeian and Keshtegar (2008), Keshavarz (2012), Nicholas and Tsusis (2002), Rozell et al, (2004). The results showed that self-awareness and self-regulation affects job satisfaction. The results of the studies are consistent with the research results of Etebarian and Omidpanah (2008), Darwish et al. (2011), NaderiAnari (2012) and Chiva and Alger (2008). The obtained results also indicate the positive impact of job satisfaction on organizational commitment. The results also indicate the positive impact of job satisfaction on organizational commitment, this means that job satisfaction in employees leads to a sense of commitment to the organization and makes employees to work better in the organization. The results are consistent with research of ShabaniBahar et al (2011), Ghamari (2011), Gholampoor et al (2010), Kabaros et al (2014), Tsai et al. (2010) and Malik et al (2010) and finally the positive effect of Selfawareness andSelf-regulation on organizational commitment with the mediating role of job satisfaction was approved which is consistent with the research of Ostovar and AmirizadehKhatooni (2008), Bazvandi et al (2013) and Golrious et al (2008). According to the results of this study it can be said that the managers of Islamic Azad University of Mashhad in particular at time of employing, through using appropriate techniques attract people with high Self-awareness andSelf-regulation, also implement training programs to improve Self-awareness andSelf-regulation, since people with high emotional intelligence have more job satisfaction and thereby their organizational commitment will be increased. People with a greater commitment to the organization, will have fewer problems such as absenteeism, resignation and dismissal from their jobs.

\section{REFERENCES:}

1. Abdarloo, A, job satisfaction a motivation to advancement and socio-economic development, analytical news, 2012, 460.

2. AbbasZadegan, M, "management on troubled organizations," Kavir Publications, Fourth Edition, Tehran, 2005.

3. Bradbury, T and Jane G, "emotional intelligence" and Mehdi Ganji and HamzehGanji, Savalan publishing, first edition, Tehran, 2005.

4. Carmeli, A, "The relationship between emotional intelligence and wok attitudes", behavior and outcomes, Journal of Managerial Psychology, 2003, 18(8): 788- 813, www.emeraldinsight.com. 
5. Ciarrochi, J, and others, "emotional intelligence in everyday life", AsgharNouriEmamZadeh and HabibollahNasiri, Neveshteh publishing, second edition, Esfehan, 2005.

6. Chao Chang, S. Ming Shing L, " A study on relationship among leadership, organizational culture, the operation of learning organization, and employees' job satisfaction, The learning organization", The Learning Organization, 2007, 14,(2): 155-185 , www.emeraldinsight.com.

7. Dolati, A, "The relationship between job satisfaction and organizational commitment of employees in the Public and Revolutionary Courts of Justice of Mashhad", MA Thesis, Management and Planning Organization, Mashhad, 2005.

8. Dehshiri, Gh, " Standardization of Emotional Quotient Inventory of Bar-On(EQI) among university students in Tehran and examining its factor structure " MA thesis, faculty of psychology of AllamehTabatabai University in Tehran, 2004.

9. Davis, Mark, "emotional intelligence tests", Mehdi Ganji, Savalan publishing, first edition, Tehran, 2005.

10. Ezzati, M. methods in the social sciences, application in the field of economics, Nour Elm Hamadan publication, 2010.

11. Goleman, D, "emotional intelligence", Nasrin Parsa, Roshd Publishing, third edition, Tehran, 2004.

12. Goleman, D. Robert J. Emmerling, "Emotional Intelligence: Issues and misunderstandings", the consortium for research on emotional intelligence in organizations, 2003, www.eiconsortium.org.

13. Goleman, D, "Emotional Intelligence Questions and Answers", www.haygroup.com, 2006.

14. Hein, S, "Emotional Intelligence for All", RoyaKouchakzadeh and MozhganMousaviShoushtari, TajassomKhallagh publishing, first edition, Tehran, 2005.

15. Houman, Heydar A, "Production and standardization of job satisfaction scale", Public Administration, 53 and 54, Winter and Fall 2001.

16. Moghimi, M, "Organization and research management approach", Termeh Publishing, Fourth Edition, Tehran. 2006.

17. Pool, Steven. Brain Pool "A management development model: Measuring organizational commitment and its' impact on job satisfaction among executives in 2007.

18. Rezaeian, A, organizational behavior management, Tehran: Tehran University, faculty of Management, 1995 
19. Siadat, A. and Marzieh. M P, "Management and Leadership with Emotional Intelligence", management, 2005, 106-105.

20. Sarooghi, A. Organizational Commitment and Its Relation With Tendency to Quit, Jornal of Governmental Administration, 1996 (35).

21. Yaghoubi, M. The relations between organizational justice and organizational commitment and job satisfaction among employees in selected hospitals of Isfahan University of Medical Sciences, Journal of Healthcare Management, 2009, (35).

\section{How to cite this article:}

Pourkiani M, Seyedi M S, Sarasia S H. The effect of self-awareness and self-regulation on organizational commitment employees of islamic azad university of mashhad with mediating role of job satisfaction. J. Fundam. Appl. Sci., 2016, 8(2S), 1886-1899. 